\title{
A Systematic Review of Personalized Learning: Comparison between E-Learning and Learning by Coursework Program in Oman
}

\author{
https://doi.org/10.3991/ijet.v14i09.10421 \\ Ragad M Tawafak ( $\bowtie)$ \\ University Malaysia Pahang, Pahang, Malaysia \\ Al Buraimi University College, Al Buraimi, Oman \\ raghad@buc.edu.om \\ Awanis Romli \\ University Malaysia Pahang, Pahang, Malaysia \\ Sohail Iqbal Malik, Mohanaad Shakir, Ghaliya Al Farsi \\ Al Buraimi University College, Al Buraimi, Oman
}

\begin{abstract}
There is a need for several applications and technologies in the higher education institutions in Oman to enhance the educational process. This systematical study investigates the simultaneous influence of technology implementation with e-learning and traditional coursework program instruction on the enhancement and development of assessment method for undergraduates in different programs. This paper aims to analyze the current articles that handle with the learning process and compare between the understanding and acceptance of E-Learning mechanism and traditional coursework method of teaching for improving assessment method and evaluation of academic performance. The method works on the benefits of increasing E-Learning process for educational skills as an assistance tool with faculty material and class discussion. In this study, surveys were distributed to two different universities and college in Oman to assess their satisfaction of learning model. The findings of this paper assisted the model that may help to improve both the teaching method and academic performance of student learning outcomes.
\end{abstract}

Keywords-E-Learning; Technology enhancement learning; Coursework program; Quality assurance, Higher educations.

\section{$1 \quad$ Introduction}

Electronic learning now a day, is a process that leads to making big changes in educations of learning and adds knowledge and usability of technologies in the last few years. Various studies shed light on huge ways of searching available information through technology tools development and its effect in enhancing the educational sector. Most universities are the attempt to increase their ranking scale and their outcomes between international competitions. This competition could be an informal way 
of assessment standard by applying accreditation requirement. The accreditation process has become more important because of adding new pieces of information's that make huge challenging in the university's outcomes and higher education institutions especially with the world needs of international faculty and student scholarship [17]. In addition, use of technology-enhanced learning (TEL) as an adaptive tool to monitor and evaluate the accreditation steps [27]; [28]; [2]. Oman's Academic Standards deposit the lowest number of necessities that the programs of study are estimated to achieve. Their major focal point is on the student learning outcomes, introducing their potential role in the society at the sensitivity of higher education institutions. These outcomes are not achieved suddenly but are the results of a cautiously deep planned and implemented official programs of study. The final assessment gives that students have accomplished at least several of the intended outcomes, and have evidence for the areas of development to progress, in cooperation with its programs and processes [26].

The comparison between E-Learning and traditional coursework learning need the standard classification method. Therefore, they test and consider the effect of modern information and easy communication can be made education easier in many variables as the collection of data is the main concern in education with assessment marks, teacher experience and knowledge, evaluation methods, and student feedback surveys [33]; [31]. The theoretical framework of any learning process used in the study consists of internal E-Learning model and institutional change theory which is applicable to the study of accreditation.

The effective use of E-Learning model help and encourage most learners for all students in diploma or bachelors to manage their work as unlimited open database and open time of use of learning, student peer observation, peer evaluation, faculty moderation instructions, videos of course materials learning. The professional work of learners in teamwork produce a trigger work to develop the assessment of course outcomes. [31]. With this concept, the data moved between factors of learning model and features to serve faculty in conducting the right assessment and delivered results to the administrator for all student achievements without missing or duplication. All of this virtual connection in continue cycle work of student-faculty-administrator and a student again, help in improving the learner confidence and their consideration of time and information type required for each assessment stage and in their knowledge skills. In addition, the learners trigger with confidence, to use different technologies or use of blended learning mechanism in a way of valuable results, student trust, and collaboration. E-Learning process as versus with personalizing learning through coursework has increased the speed of getting different types of material, best optional opinion, converting knowledge, concluding new suggestions for both faculty and learner. The method is about learning and teaching thinking of accepting and applying mix method of learning and technology development [33]; [23]; [30].

Standard assessment basically produces a self-assessment in contrast to the standards. It also outlines briefly if or not the HEI has agreeably attained the level of acceptance and recommendation in its earlier quality report. The outcome of this step of assessment, the research focuses on some important factors such as firstly, the students learning by coursework programs to show the real output of universities that 
include some factors like student motivation and perception, learning acceptance, interactivity, student satisfaction, and academic performance. Secondly, the faculty qualification that all standard criteria should be based on the qualification and experience of the teaching staff that explain the factors of teacher subject knowledge, course content, and assessment acceptance. Finally, the university outcomes of the learning process related to factors: perceived ease of use, perceived usefulness, technology integration, and continue to use E-Learning.

The technology enhancement learning techniques give flexibility and freedom to the faculty to select the proper assistance applications in course enhancement and motivated students to more understanding. The selection of the right application gives beneficial results of using E-Learning techniques with teaching experience in assessment to improve both academic performance and developing teaching assessment methods with updated requirements for education institutions. The main contribution of this study lies in showcasing the previous studies that focused on the E-Learning methods to improve academic performance in universities, and investigating the mechanism through which this relationship is analyzed, developed, and implemented for better evaluation results[8];[9] [31]; so that the efforts of the teaching staff will be categorized to give high student outcomes on fixed matched standard exams [25].

The new development of technology, in addition, the use of mobile and portal laptops with huge of community connections and sharing, guide students to view how they learn, develop, experiment, inquire and reflect effects based on past experiences to re-built, design and implement the new techniques in teaching and learning. There are many external application tools added to learning of education. Using these applications (wiki chat, video Blog, Google forms or e-learning model linked with student portal system, different adapted programming language, and software applications) all used as inter-conversation online chat that give chance to students to learn from other students [24]; [14]; [29].

\section{Research Objectives}

The need to develop an enhanced framework including a model that uses an electronic advanced tool to increase the contact between student groups in a course outside the classroom and improve its objective. This model outcomes linked with electronic develops on assessment and directing the assessment method by faculties depends on their experience and training for teaching method implementation. The enhanced learning level shows the moderation development in all assessment process steps between candidate faculties that make student grades satisfied and trusted.

\section{$3 \quad$ Literature Review}

As a previous study of historical articles to traditional and classical learning as "use of standard books and class attended to study on fixed time and real communication with the teacher" to a virtual method of learning" use of E-Learning model" [23]. Furthermore, E-Learning or any online education system related to improving self- 
regulation and self-efficiency [10]. They used the type of blended learning as a mixer them in the responsibility of learning and develop technologies used. The interested learner with E-Learning has a concern with the accuracy of participant students their perception on improving their academic performance [3]; [31]; [29].

\subsection{Student learning by coursework programs}

This area includes the importance of teaching, programs, and assessments. The focus here is on the organization of institutional systems for excellent supervision of students by coursework, and not on the specific programs themselves. All HEI must understand the importance of quality and its significance in their programs and armed forces. These points include the graduate attributes and student learning objectives, curriculum, student entry standards, teaching quality, plagiarism, student placements, assessment methods, standards and moderation, academic security and invigilation, student retention and progression, graduate destinations and employability [5];[6]. These are fundamentally considered as the criteria for one complete set.

[2] Developed a continuous improvement process of coursework learning and its implementation in engineering programs with five different majors at Qassim University, Saudi Arabia. This improvement process depends on integrated strategies that focus on the implementation of a structure that converts objectives into valuable measured outcomes of identifying student learning outcomes and improving their academic performance and gives feedback for corrective measures through each test in the program checkpoint. The method is based on two assessment of university work and documents cycles: the slow process with programs that examines the outcomes [5], and the fast process that refers to the degree of student's assessment in each exam, homework or assignment and how graduates achieve their target of success through the slow loop. The outcomes should be based on the ability to function as a team; then, the performance will be achieved by gathering information and finding the role performed by the team through sharing and listening to the group. Finally, it measures the educational process by evaluating and assessing the programs. This is related to the skills, behavior, and level of knowledge of the students using the traditional learning process [29].

[21] Proposed an application for quality improvement, learning process test and increased capability by conducting an internal evaluation (self-evaluation) to guide the departmental management at the universities on teaching style and achieved targets with the learners [4]. The method used was a meta-analysis, and such an SPSS statistical data domain functions by giving reports, factor tests and selected samples to make the analysis, depending on the purpose of the sampling method. The results of this study gave a good significant indicator to successful management for universities with culture evaluation, submitted through coursework of learning in improvement. It also agrees that internal evaluation of the course contents, results achieved, and student learning outcomes accomplished as an important function is a mechanism which gives proper results. 


\subsection{Self-regulation of e-learning}

In the recent increase of development based on learner (student) learning and on them implementing an active part with the creation of facts. The faculty's role in this stage is to guide, monitor the process and student's needs. There are many over times a change and adjustment in the way of looking to the learning process in higher education's [28]. Therefore, there is an emerging shift that displaces the process emphasis on the teacher to a prospective learner. This means that it is gradually increased recognized the active role of the learner in the learning process as same as in traditional learning of serious effect and full focus on course discussion. The demands placed at this stage from students to achieve success, share knowledge, require him to learn new skills such as flexibility, the courage of decision, responsibility, independence and being active and expert. New predictors of academic success are placed in the ability to manage the learning process itself [10]; [19]; [34].

\subsection{The quality of student achievement as SLOs using e-learning}

With the continues development on technologies of learning, the demands of society still urge to changes in the learning environment. E-Learning gives students time and flexibility of reading and work, allowing them more freedom in sharing and find the suitable management for their needs [11]; [28]. In an early stage of the study, the whole consideration is to focus on student learning outcomes and the target achieved in each exam or assessment to enhance the academic performance. The coursework of learning and education answer the case of how students have been carried with uniqueness standard by using the fundamental resource of learning? Also, how could the students accomplish their outcomes without using any additional technology? and How the use of E-Learning model in education can develop the accomplish professional outcomes in easy way of learning? [12]; [11]; [28].

The learner is the main target of the whole learning mechanism process. Furthermore, the faculty, course, and continued use of E-Learning as a secondary target between a lot of existing technologies involved such as a BLOG, an email, chatting applications, use of Google forms, open forum with peer evaluation, all viewed as different applications with privileges on different operating systems. When student used these technologies, they might be better developed, more confidence, the open mind of access and sharing knowledge and so on. The blended learning as the sample of E-Learning involves many learning types and communication service [13]. In online courses without the use of face to face communication with most active application techniques allowed, or aid used technology course material, Students can access the open access courses; by using their email and passwords; submit their homework and projects through this system. An alert email sent to faculty in each uploaded file. Additionally, they are allowed to choose how they will access the necessary learning materials and select a suitable group to join the sharing material. [22], they define different use of technology in the learning process as blended learning. "Blended learning combines face-to-face with distance delivery systems but it's more than showing a page from a website on the classroom screen those who use blended learn- 
ing environments are trying to maximize the benefits of both face-to-face and online methods (p. 229)" [15].

Students in E-Learning or type of technology development require more selfmotivation and self-determination to cross passing of their academic goals [21]; [34]. This development can lead the learners to learn in great feedback on learning strategy and give them the desired confidence. Working in virtual environments, from the learner point view, has implications and behavioral changes in their performance. It is necessary that they are aware that there is a close relationship between the virtual environments, motivation, and self-regulation of the learner. This reason due to freedom of learning that implies to great responsibility of students.

At the end of summarized work, the mixing technologies as blended learning of multi resources, such as example of use multimedia programs, peer-student motivation, Wiki-online chat program with internet access and use, this help to develop learning, which can be happen in any setting and at any time (at school, at university, at home, in leisure spaces, among others). This feature of the absence of spatiotemporal constraints combined, also, with the need for lifelong learning is the basis of new educational scenarios and changes in the relationships that are established between the different actors in the teaching-learning process [10].

In addition, from these studies, it has emerged that students consider web-based online learning environment effective, and trusted enough, but not a replacement for face-to-face instruction between faculty and student classmate. Further, compared to traditional classroom model, E-Learning has been observed to be superior on important parameters like student satisfaction, motivation, assessment acceptance, dropout rate, attitude, academic performance, knowledge retention, intention to use ELearning model and development of analytical skills [29]; [38]. On the other side, an ADRI based approach was introduced in computer programming education to promote interaction between faculty and student [35]; [36]; [37]; [39].

\subsection{Communication skills}

Transparency has been identified as the most important requirement for communication skills. For example, the IT auditor stated that the organization of quality assurance development programs with the professional, technical and experienced staff frequently will be good in following the security system and checking the confidentiality of teachers, administrators, and students with a common TEL communication application. These technologies give the flexibility to work with physical location and ease of reporting participation if they use the main channel and portal system authority. Also, the communication skills based on moderator levels, where many factors are checked as an allocation of selected course, educational level between diploma and bachelor, subject matter of majors, duration of learning course, communication type and quizzes style and assess [28]. 


\section{Discussion}

This study examined what role accreditation plays in a student selecting ELearning program in compare with coursework program. Large universities were selected as the site to conduct the research, and two universities were chosen to survey students. An internet-based survey was used for data collection, and pilot testing and a panel of experts were utilized prior to the survey being distributed. The data collected was mixed of closed-ended quantitative questions and Open-ended qualitative questions. The methodology and suggested models identified depend on disadvantages and challenges of previous studies from related works. The models give an improvement process and accuracy results through smart PLS validation program. The paper used an existing model of UCOM that applied in Oman universities, then the results of student feedback on applying both traditional process and E-Learning model process are evaluated and analyst using the above literature and previous system implementation significantly acceptance [29].

The quality assurance department is responsible for monitoring, controlling and extracting the results from the whole mechanism of evaluating the personalize learning effects to identify the misunderstanding in the approval of personalizing learning effect processes developed by UCOM as E-Learning model in connection with coursework system [29]. Personalized learning are positive outcomes in many studies that consider the real contact and stick with fixed learning time can affect significantly good with young learners who still not much familiar with a technology element. The E-Learning framework is responsible for connecting the different techniques and models in the general frame by activating the strangeness of using TEL technology to improve the whole education performance.

The magnitude of any system is its progress in complexity and completeness as continuous variables. When manipulating E-Learning model, it is important to realize that it is conditional on a variety of sometimes contradictory internal and external aspects [32]. For this reason, its design framework becomes necessary when considering research with a reasonable discussion on worldview so, that there will be justification for the truth of a proposal, and that validation can stand to examine the relevant facts over a specific period. It is equally important to address the study of reality, how meaning is constructed, a system of methods used in an area of activity or study. The acceptability of research by the community of interest is a necessary element in rigorous research.

The initial perspectives reveal satisfactory researches, produces data which is philosophically and methodologically consistent, include a good problem statement, design quality, sampling, measurement, analysis (based on data categorizations made by the researcher, how noticeably the categorizations illustrate the understanding being made, and how they relate to the research question), validity and reporting based on methods, and community of interest reception of the research. The study entailed the beginning of a model, joining the theoretical foundations of electronic programs used in E-learning and Blended learning. Suggestions were extracted from the reproduction of previous studies and experienced practitioners. 


\section{Conclusion}

In conclusion, the researchers in the tackled papers reviewed many studies related to the coursework learning process and its advantages on the stable movement toward student degree and the E-Learning model that used as assistance model with traditional work to improve and develop the educational process. This paper gives suggestions for student's course performance can be tested and evaluated; students and teachers can meet online and realize interactive learning activities. The point of using technology system is to increase the whole achievements of SLO that matching with developing quality assurance strategies. From the systematic review of many studies, the researchers conclude that E-Learning with online models are very easy and more motivated by joined students and help them in the enhancement of their academic performance.

In the future work, the authors try to use an enhanced model of one of the existing models to include more expert faculties, and to make an interview with selected candidates, in addition, quality manager and dean, asking them to identify more active points that could add valuable targets to the model and improve the level of academic performance of the students with concurrently reducing assessment efforts of faculties with continues electronic material to give more justification of the whole assessment process.

This study phased some limitations. Still, the number of studies that explain the importance of existing coursework as enough without the need to E-model as assisting model in the educational process is less and not clearly describe the gap or weakness of keeping only traditional way of learning in the future of learners. However, the main problem of converting traditional to more enhanced technology is the faculties less experience in technology development. This important factor makes the real power use of E-Learning models not in huge difference from the traditional method.

\section{Acknowledgement}

This research received no specific grant from any funding agency in the public, commercial, or not-for-profit sectors. This work is supported by the University Malaysia Pahang Term. These supports are appreciated. Also, the authors would like to express their gratitude and appreciation to the reviewers.

\section{$7 \quad$ References}

[1] Adwan, j. dynamic online peer evaluations to improve group assignments in a nursing elearning environment. nurse education today (2016).41, 67-72. https://doi.org/10. 1016/j.nedt.2016.03.028

[2] Alyahya, s. a., \& abo el-nasr, a.-b. a. (november 6-8,2012). Outcomes-based assessment of the engineering programs at Qassim University for abet accreditation. international conference on interactive mobile and computer aided learning (imcl) (pp. 22-31). amman, jordan: 978-1-4673-4925-3/12/\$31.00 C2012 ieee. https://doi.org/10.1109/imcl.2012.6396445 
[3] Benson, p. teaching and researching: autonomy in language learning. london: routledge. (2013).

[4] Betts, f. how systems thinking applies to education. educational leadership, (1992). 50(3), $38-41$.

[5] Carroll, m., razvi, s., goodliffe, t., \& al-habsi, f. progress in developing a national quality management system for higher education in oman. quality in higher education, (2009). 15(1), 17-27. https://doi.org/10.1080/13538320902731328

[6] Carrell, s., \& west, j. e. does professor quality matter? evidence from random assignment of students to professors. journal of political economy, (2010). 118(3), 409-432. https://doi.org/10.1086/653808

[7] Chen, c. c., \& jones, k. t. blended learning vs. traditional classroom settings: assessing effectiveness and student perceptions in an mba accounting course. journal of educators online, (2007). 4(1), n1.https://doi.org/10.9743/jeo.2007.1.3

[8] Chmiel, a. s., shaha, m., \& schneider, d. k. introduction of blended learning in a master program: developing an integrative mixed method evaluation framework. nurse education today/science direct- elsevier, (2017).172-179. https://doi.org/10.1016/j.nedt.2016.10.008

[9] Debicki, b. j., kellermanns, f. w., barnett, t., pearson, a. w., \& pearson, r. a. beyond the big five: the mediating role of goal orientation in the relationship between core selfevaluations and academic performance. elsevier, (2016). 273-285. https://doi.org/10.10 $\underline{\text { 16/j.ijme.2016.05.002 }}$

[10] De fátima goulão, m., \&menedez, r. c. learner autonomy and self-regulation in elearn-ing. procedia-social and behavioral sciences, (2015). 174, 1900-1907. https://doi.org/10. 1016/j.sbspro.2015.01.853

[11] Goulão, m. f. the relationship of e-learner's with studies strategies to support learning. procedia - social and behavioral sciences, (2014). 116362 - 367 https://doi.org/10.1 016/j.sbspro.2014.01.222

[12] Hashim, a. a., \& majid, m. a. effects of video display terminal resolutions to the leg-ibility of text on a web page. international journal of software engineering and computer systems, (2015). 1(1), 131-157. https://doi.org/10.15282/ijsecs.1.2015.11.00011

[13] Joseph, j. the barriers of using education technology for optimizing the educational experience of learners. procedia-social and behavioral sciences, (2012). 64, 427-436. https://doi.org/10.1016/j.sbspro.2012.11.051

[14] Lancaster, j. w., wong, a., \& roberts, s. j. 'tech'versus 'talk': a comparison study of two different lecture styles within a master of science nurse practitioner course. nurse education today, (2012). 32(5), e14-e18. https://doi.org/10.1016/j.nedt.2011.09.018

[15] Kumar, r., \&pande, n. technology-mediated learning paradigm and the blended learning ecosystem: what works for working professionals? procedia computer sci-ence, (2017).122, 1114-1123. https://doi.org/10.1016/j.procs.2017.11.481

[16] Liu, c., \& chen, 1.-m. (march 29-31, 2012). selective and objective assessment cal-culation and automation. acmse' 12 , tuscaloosa, al, usa.

[17] Laborda, j. g., caroli, m. e. d., \&sagone, e. 4th world conference on learning teaching and educational leadership (wclta-2013) generalized self-efficacy and wellbeing in ado-lescents with high vs. low scholastic self-efficacy. procedia-social and behavioral sci-ences, (2014).141, 867-874. https://doi.org/10.1016/j.sbspro.2014.05.152

[18] López-pérez, m. v., pérez-lópez, m. c., \& rodríguez-ariza, 1. blended learning in higher education: students' perceptions and their relation to outcomes. computers \& education, (2011). 56(3), 818-826. https://doi.org/10.1016/j.compedu.2010.10.023 
[19] Macejka, m. the role of grade level and locus of control in self- regulated learning strategies of college students. journal of education, psychology and social sciences, (2014). 1(2), $1339-1488$

[20] Marquis, g. p., \& ghosh, s. student preferences for a hybrid course. journal of education for business, (2017). 92(3), 105-113.

[21] Mohammadi, r., eshaghi, f., \&arefi, m. internal evaluation: appropriate strategic for quality evaluation and improvement of management in departments at universities (the case of iran). international conference on education and beducational psychology (iceepsy 2012) (pp. 719 - 728). procedia - social and behavioral sciences 69/elsevier. https://doi.org/10.1 016/j.sbspro.2012.11.466

[22] Osguthorpe, re, graham, c.r. blended learning environments. definitions and directions, the quarterly review of distance education, 2003, vol. 4 no.3, 227-233.

[23] Posey, 1., \&pintz, c. transitioning a bachelor of science in nursing program to blended learning: successes, challenges \& outcomes. nurse education in practice, (2017).26, 126133. https://doi.org/10.1016/j.nepr.2016.10.006

[24] Salajan, f. d., \& mount, g. j. leveraging the power of web 2.0 tools: a wiki platform as a multimedia teaching and learning environment in dental education. journal of dental education, (2012).76(4), 427-436.

[25] Strang, k. d. university accreditation and benchmarking: pedagogy that increases student achievement. international journal of educational research, (2013).62, 210-219. https://doi.org/10.1016/j.ijer.2013.09.007

[26] Schneider, c. g. policy priorities for accreditation put quality college learning at risk. liberal education fall (2016). 2015, 24

[27] Tawafak, r. m., mohammed, m. n., arshah, r. b. a., shakir, m., \&mezhuyev, v. technology enhancement learning reflection on improving students' satisfaction in omani universities. advanced science letters, (2018). 24(10), 7751-7757. https://doi.org/10.1 $\underline{166 / a s l .2018 .13012}$

[28] Tawafak, r. m., romli, a. b., bin abdullah arshah, r., \&almaroof, r. a. s. assessing the impact of technology learning and assessment method on academic performance. eurasia journal of mathematics, science and technology education, (2018).14(6), 2241-2254. https://doi.org/10.29333/ejmste/87117

[29] Tawafak, r. m., romli, a. b., \& bin abdullah arshah, r. continued intention to use ucom: four factors for integrating with a technology acceptance model to moderate the satisfaction of learning. ieee access. (2018). https://doi.org/10.1109/access.2018.2877760

[30] Tawafak, r. m., mohammed, m. n., arshah, r. b. a., \&romli, a. review on the effect of student learning outcome and teaching technology in omani's higher education institution's academic accreditation process. in proceedings of the 2018 7th international conference on software and computer applications (2018, february). (pp. 243-247). acm. https://doi.org/10.1145/3185089.3185108

[31] Tawafak, r. m., romli, a. b., \&alsinani, m. e-learning system of ucom for improving student assessment feedback in oman higher education. education and information technologies, (2018). 1-25. https://doi.org/10.1007/s10639-018-9833-0

[32] Van grembergen, w., de haes, s., \&guldentops, e. structures, processes and relational mechanisms for it governance. retrieved 17 march 2017, from idea group publishing: (2004). https://doi.org/10.4018/9781591401407.ch001

[33] Wilson, s. m., \& youngs, p. research on accountability processes in teacher education. in \&. k. m. cochran-smith, studying teacher education: the report of the aera panel on research and teacher education (pp. pp. 591-643). washington: dc: american educational research association. (2005). https://doi.org/10.4324/9780203864043 
[34] Zimmerman, b.j. becoming a self-regulated learner: an overview. theory into practice, (2002).41(2), 64 - 70 https://doi.org/10.1207/s15430421tip4102_2

[35] Malik, s.i., \& coldwell-neilson, jo. (2017). impact of a new teaching and learning approach in an introductory programming course, journal of educational computing research, sage, vol. 55, no. 6, pp. 789-819, 2017, https://doi.org/10.1177/0735633116685852

[36] Malik, i. s., \& coldwell-neilson, j. (2017). comparison of traditional and adri based teaching approaches in an introductory programming course. journal of information tech-nology education: research, vol. 16, pages. 267-283. retrieved from HTTP://WWW.INFORMINGSCIENCE.ORG/PUBLICATIONS/3793. https://doi.org/10.28945/3793

[37] Malik, i. s., \& coldwell-neilson, j. (2016). a model for teaching an introductory programming course using adri. education and information technologies. https://doi.org/10.1 $\underline{007 / \mathrm{s} 10639-016-9474-0}$

[38] Malik, i. s., mathew, r., al-nuaimi, r., al-sideiri, a., \& coldwell-neilson, j. (2019). learning problem solving skills: comparison of e-learning and m-learning in an introduc-tory programming course, education and information technologies. https://doi.org/10.1007/s10639$\underline{019-09896-1}$

[39] Malik, i. s., al-naseeri, m., eldow, a., ashfaque, m.w. (2019). promoting algorithmic thinking in an introductory programming course, international journal of emerging technologies in learning. https://doi.org/10.3991/ijet.v14i01.9061

\section{Authors}

Ragad M. Tawafak received the bachelor's degree with a focus on expert system of bacteria classification project and the M.Sc. degree (Hons.) in computer science from AlMousel University, Iraq, with a focus on hybrid neural network and genetic algorithms. She is currently pursuing the Ph.D. degree in computer science with the University Malaysia Pahang. She was with the Software Engineering Department, AlMustansryia University, Iraq, for four years. She was with the Oman College of Management and Technology for two years. She has been a Lecturer with the Information Technology Department, Buraimi University College, Oman, for over 12 years. Most of her publications were indexed under Scopus. Her current research interests include e-learning, Blended learning, Image Processing, technology adoption and acceptance, and academic performance.

Awanis BT Romli, is currently a Senior Lecturer at Universiti Malaysia Pahang (UMP), Malaysia with more than 10 years' experience as an academic lecturer at Faculty of Computer Systems \& Software Engineering, UMP. I received my PHD in Engineering from Cardiff University, UK. I am able to work in a managerial role or as part of team and having the proven ability to successfully work to tight schedules and deadlines. I hold various responsibilities in the administrative and academician works. Currently, I am the Head of Computer Science Program, fellow of Centre for Academic Innovation \& Competitiveness (CAIC), project leader for the research grants and expert panel for the database course. My research expertise are in knowledge management, integrated system, decision making, e-learning and sustainable engineering. I have published more than 10 publications in international journals and 20 publications in international conference proceedings. Moreover, I have shown an 
excellent achievement in research competition by wining gold medals in research exhibitions locally and internationally.

Sohail Iqbal Malik obtained his Ph.D. in Computer Science from Deakin University, Australia. He has been working as an Assistant Professor at Information Technology Department, Buraimi University College, Oman (Academic collaboration with California State University, Northridge, USA) since February 2007. His research interest includes Algorithmic Thinking, Computer Education, Technology in Education, and Mobile Learning.

Mohanaad Shakir is an Assistant Professor at Al-Buraimi University College, Oman. He holds a B.S.C Degree in Computer Science from the University of Almamoon, Baghdad, Iraq; Post Diploma in Computer Security from University of Technology, Iraq and M.Sc. in Information Technology (MIT) from the University of Tenaga National (UNITEN), Putrajaya, Malaysia. He is a Ph.D. candidate in Information Communication Technology at the University of Tenaga National (UNITEN), Putrajaya, Malaysia. His research interests include Cipher Security, Data classification, Computer-Aided Learning and Cloud Computing Security. He can be contacted at mohanaad@buc.edu.com

Ghaliya Al Farsi she is lecturer of IT department at BUC College, her graduated of MSc in computer science from Sohar Univeristy in 2015.

Article submitted 2019-03-06. Resubmitted 2019-04-16. Final acceptance 2019-04-16. Final version published as submitted by the authors. 